\title{
Absolute Assignment of Constitutional Isomers via Structurally Diagnostic Fragment Ions: The Challenging Case of $\alpha$ - and $\beta$-Acyl Naphthalenes
}

\author{
Mario Benassi and Marcos N. Eberlin \\ Thomson Mass Spectrometry Laboratory, Chemistry Institute, University of Campinas-UNICAMP, \\ Campinas, Brazil
}

\begin{abstract}
A general mass spectrometric method is described for the absolute assignment of $\alpha$ - or $\beta$-acyl naphthalenes, via which the gaseous $\alpha$ - and $\beta$-naphthoyl cations of $m / z \quad 155$ are used as structurally diagnostic fragment ions $(S D F I)$. These stable acylium ions are common and normally abundant fragment ions of acylnaphthalenes in general. Using a pentaquadrupole mass spectrometer, CID experiments with argon and ion/molecule reactions with 2-methyl1,3-dioxolane, isoprene, acetonitrile and propionitrile were performed but failed to distinguish the two SDFI. Reactions with ethyl vinyl ether and several homologues as well as ethyl vinyl thioether were, however, successful. In reactions with ethyl vinyl ether, the $\alpha$-SDFI form a pair of diagnostic product ions of $m / z 165$ and $m / z$ 181, which are absent in the corresponding spectrum of the $\beta$-SDFI. Methyl 4-(1-naphthyl)-2,4-dioxobutanoate was used as a test molecule for this class of constitutional isomers and absolute structural assignment as an $\alpha$-acyl naphthalene was correctly performed via the characterization of its $\alpha$-SDFI. (J Am Soc Mass Spectrom 2010, 21, 2041-2050) (C) 2010 American Society for Mass Spectrometry
\end{abstract}

$\mathrm{T}$ The absolute assignment of configuration for a molecule that belongs to a class of constitutional isomers with similar chemical properties such as cis/trans and ortho/meta/para isomers is often a challenging task. To elucidate its correct connectivity or spatial distribution, instrumental techniques able to provide fine structural details are required, and for this task, nuclear magnetic resonance spectroscopy (NMR) [1] has been often mandatory. NMR can perform absolute assignment of configuration and distinguish most types of constitutional isomers but its sensitivity is several orders of magnitude less than mass spectrometry (MS), whereas coupling of NMR to separation techniques such as GC, LC, and CE has been not straightforward $[2,3]$.

MS analysis is usually much faster than NMR and applicable to considerably much smaller amounts of sample. MS is also efficiently coupled to most separation techniques. MS is, however, intrinsically unable to perform absolute structural assignment of constitutional isomers. For this task, MS normally relies on comparisons of mass or tandem mass spectra data

Address reprint requests to Dr. M. N. Eberlin, Thomson Mass Spectrometry Laboratory, Institute of Chemistry, University of Campinas-UNICAMP, 13083-970 Campinas, Brazil. E-mail: eberlin@iqm.unicamp.br obtained from isomeric sets of pre-characterized molecules. The whole set of isomers must therefore be available and a case-by-case comprehensive set of reference spectra must be created. But even when this set is available, mass spectra are sometimes too similar failing to assist configuration assignments. A general rule or strategy applicable to the MS assignment of configurations via a noncomparative fashion for all members of a given class of isomers is even more challenging to establish. When dealing with a single and novel molecule for which no reference spectra is available, MS data itself is therefore of limited use for the absolute assignment of a constitutional isomer.

Recently, however, we have proposed [4-10] a strategy to deal with this MS limitation. We argue that molecules within a given class tend to dissociate to a common fragment ion, and that if such ions could be distinguished, they would function as reference ions for the general and absolute structural assignment of any parent molecule within the class. This strategy is based therefore on the expectation that most (ideally all) molecules within the isomeric class would form the selected and structurally diagnostic fragment ion (SDFI) upon ionization and dissociation. Ideally, the SDFI need to be stable gas-phase ions to increase the probability of their formation as common and abundant fragment ions within the class. The SDFI may isomerize to a more stable structure but SDFI should not interconvert. Ions with such properties would serve as reference for the 
entire isomeric class if they could be differentiated; thus revealing the configuration of the parent molecule. To be differentiated, these SDFI should display characteristic unimolecular dissociation and/or bimolecular chemistry. Proper SDFI are therefore the "holy grail" for this strategy. We have devoted our efforts in finding proper SDFI for several classes of constitutional isomers such as $\mathrm{N}$-alkyl versus ring substituted or isomers differing on the position of ring substitution for alkylanilines [4], pyridines [7], pyrimidines [7], nitrobenzenes [9], furanes and thiofuranes [8], acyl and amidyl anilines [9], acyl benzenes [6] and pyrroles [10]. Begala et al. [11] have also used the SDFI strategy to differentiate isomers of 6-alkyl and 6-aryldibenzo(d,f) $(1,3)$ dioxepines by performing CID on 2-substituted benzofuran diagnostic ions.

CID is often the technique of choice for structural investigation, but chemistry has also demonstrated the existence of a direct, rational, and often elegant relationship between molecular structure and biomolecular reactivity. Ion/molecule reactions performed in the gas-phase environment of mass spectrometers have therefore been shown to be an effective approach to probe the reactivity and structure of gaseous ions and molecules [12-15]. CI is a classic example of the use of ion/molecule reactions for structural investigations in MS [16], but reactions of pre-isolated ions performed under more controlled conditions have also been studied widely. For instance, Drewery and Jennings have studied the intrinsic reactivity of methyl vinyl ether [17] and $[2+4]$ cylcloadditions of ethyl and methyl vinyl ether with ionized 1,3-butadiene [18]. Greenwold and Gross also investigated cycloadditons of ionized vinyl methyl ether with 1,3-butadiene [19], and the analytical applications of such reactions to differentiate $\mathrm{C}_{5} \mathrm{H}_{10}$ isomers [20], whereas Brodbelt and coworkers [21] and Kenttämaa and Cooks [22] have also used ion/molecule reactions with methyl vinyl ether to probe the structure of protonated forms of isomeric organic molecules and drugs [23]. For potential SDFI therefore, one should broadly scrutinize both their CID and bimolecular ion/ molecule reactivity in trying to achieve unambiguous differentiation.

Acyl naphthalenes form an important class of chemicals with many applications such as substrates for the syntheses of peroxy-containing acetylenic alcohols and ethers [24], radicals initiator for polymerization [25], phototrigger inhibitors of termite survival [26], precursors for the preparation of some thiocarbonyl compounds that are important in chlorophyll a synthesis [27], and precursors for photocycloaddition studies of intramolecular rearrangements [28]. In this study, we have tested the SDFI strategy for $\alpha$ - and $\beta$-acyl naphthalenes, an important class of constitutional isomers.

\section{Experimental}

$\mathrm{MS}^{2}$ and $\mathrm{MS}^{3}$ experiments were performed on an Extrel (Pittsburgh, PA, USA) mass spectrometer, denoted as
$\mathrm{Q}_{1} \mathrm{q}_{2} \mathrm{Q}_{3} \mathrm{q}_{4} \mathrm{Q}_{5}$, which is described in detail elsewhere [29]. The instrument is composed of a sequential arrangement of three mass analyzing quadrupoles $\left(Q_{1}, Q_{3}, Q_{5}\right)$ and two "rf-only" ion focusing reaction quadrupoles $\left(\mathrm{q}_{2}, \mathrm{q}_{4}\right)$. The qs can perform ion/molecule reactions as well as collision induced dissociation (CID) [30]. The structurally diagnostic fragment ions (SDFI) tested were generated by dissociative $70 \mathrm{eV}$ EI from the precursors $\alpha$-acetonaphthone (98\%) and $\beta$-acetonaphthone (99\%) purchased from Sigma-Aldrich (St. Louis, MO, USA).

CID experiments $\left(\mathrm{MS}^{2}\right.$ were performed with the SDFI using argon as collision gas. The ions were selected by $\mathrm{Q}_{1}$ and directed towards $\mathrm{q}_{4}$ filled with argon. The ion translation energy was set at $15 \mathrm{eV}$. The ionic fragments are detected by scanning $Q_{5}$ whereas $q_{2}$ and $\mathrm{Q}_{3}$ were operated in the broad band $r f$-only mode. The ion/molecule reactions were performed via $\mathrm{MS}^{2}$ experiments. For such experiments, $\mathrm{q}_{2}$ was filled with neutral molecules of interest and the ion translational energy was set to near $0 \mathrm{eV}$. The product ions generated in $q_{2}$ were directed to $Q_{5}$ for spectra acquisition. The CID behavior of the product ions were also evaluated by $\mathrm{MS}^{3}$ experiments. $\mathrm{Q}_{3}$ was then used to select a product ion of interest and $\mathrm{q}_{4}$, filled with argon, caused its CID whereas $Q_{5}$ was scanned to acquire the spectrum.

\section{Results and Discussion}

As a reference pair of isomers, $\alpha$ - acetonaphthone and $\beta$-acetonaphthone (Scheme 1) were used in the search for proper SDFI for this isomeric class. Note that the choice of a pair of isomers, and the acetonaphthone pair specifically, is just fortuitous (guided by commercial availability) since any set of $\alpha$-acyl and $\beta$-acyl naphthalenes (not necessarily an isomeric pair) forming both the selected SDFI would function as well. As Figure 1 shows, the $70 \mathrm{eV}$ EI-MS for both $\alpha$ and $\beta$-isomers $\mathbf{1}$ and 2 are nearly identical, with three major ions of $m / z 127$, $155, \mathrm{~m} / \mathrm{z} 170$. Both the molecular ions of $\mathrm{m} / \mathrm{z} 170$ lose a methyl radical to form the respective acylium ions $\mathbf{1 a}$ and 2a of $\mathrm{m} / \mathrm{z} 155$ (Scheme 1), whereas further dissociation by loss of $\mathrm{CO}(28 \mathrm{Da})$ produces the isomeric naphthyl cations $\mathbf{1} \mathbf{b}$ and $\mathbf{2} \mathbf{b}$ of $\mathrm{m} / z \mathbf{1 2 7}$. Ionized $\mathbf{1}$ and $\mathbf{2}$ show very similar dissociation chemistry and this similarity illustrates the difficulties in performing configuration assignment and to distinguish isomeric sets of acyl naphthalenes by mass spectrometry, even when working with pre-characterized molecules.

The isomeric $\alpha$ - and $\beta$-naphthoyl cations 1a and 2a of $\mathrm{m} / \mathrm{z} 155$ (aromatic acylium ions) are abundant and seem to display the attributes for proper SDFI in regard to high stability and probability to be formed as abundant fragments. The $\alpha$ - and $\beta$-naphthyl cation ions $\mathbf{1 b}$ and $\mathbf{2 b}$ of $\mathrm{m} / \mathrm{z} 127$ (Scheme 1) are also abundant but they might interconvert by hydride migration. Ions $\mathbf{1} \mathbf{b}$ and $\mathbf{2} \mathbf{b}$ were 
(a)<smiles>CC(=O)c1cccc2ccccc12</smiles>

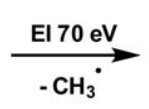<smiles>O=Cc1cccc2ccccc12</smiles><smiles>CCOCCOC(C)C</smiles>

(b)<smiles>CC(=O)c1ccc2ccccc2c1</smiles><smiles>CC(=O)CC=[C+]c1ccc2ccccc2c1</smiles><smiles></smiles>

Scheme 1

extensively investigated in regard to their CID and ion/molecule chemistry, but found to display limited and very similar reactivities (data not shown).

\section{CID Behavior of the Potential SDFI}

Due to their acylium ion nature and hence potentially high (and diverse) reactivity, the abundant naphthoyl cations $1 \mathbf{a}$ and $2 \mathbf{a}$ of $\mathrm{m} / \mathrm{z} 155$ were comprehensively investigated. The CID spectra of both isomers (Figure 2) displayed similar dissociative behavior dominated by the loss of $\mathrm{CO}$ and a minor fragmentation leading to the phenyl cation of $m / z$ 77. Although the intensity ratios may appear slightly different, these ratios are not reproducible enough to allow secure differentiation. The CID chemistry is useful however to confirm the formation of $\mathbf{1 a}$ and $\mathbf{2 a}$ for further investigation of their ion/molecule chemistry, see below.

\section{Reactivity Towards Transacetalization with 2-Methyl-1,3-Dioxolane}

Acylium ions are known to react readily with acetals by transacetalization [31-34] yielding resonance stabilized cyclic ionic acetals. In an effort to distinguish the isomeric $\mathbf{1 a}$ and 2a, reactions with 2-methyl-1,3-dioxolane were performed (Figure 3). Unfortunately, although both the $\alpha$ - and $\beta$-isomeric ions reacted similarly and to great extents to form the resonance stabilized cyclic 1,3dioxolanylium of $\mathrm{m} / \mathrm{z} 199$ (Scheme 2), their product ion mass spectra were nearly identical and therefore undistinguishable. Despite of the use of very low collision energy (near $0 \mathrm{eV}$ ), fragmentation also occurred yielding the respective $\alpha$ - and $\beta$-naphthyl cations $\mathbf{1 b}$ and $\mathbf{2 b}$ of $m / z$ 127. In a further attempt to distinguish the isomers, the isomeric products of $\mathrm{m} / \mathrm{z} 199$ were selected and dissociated via MS $^{3}$ experiments (Figure S1, which

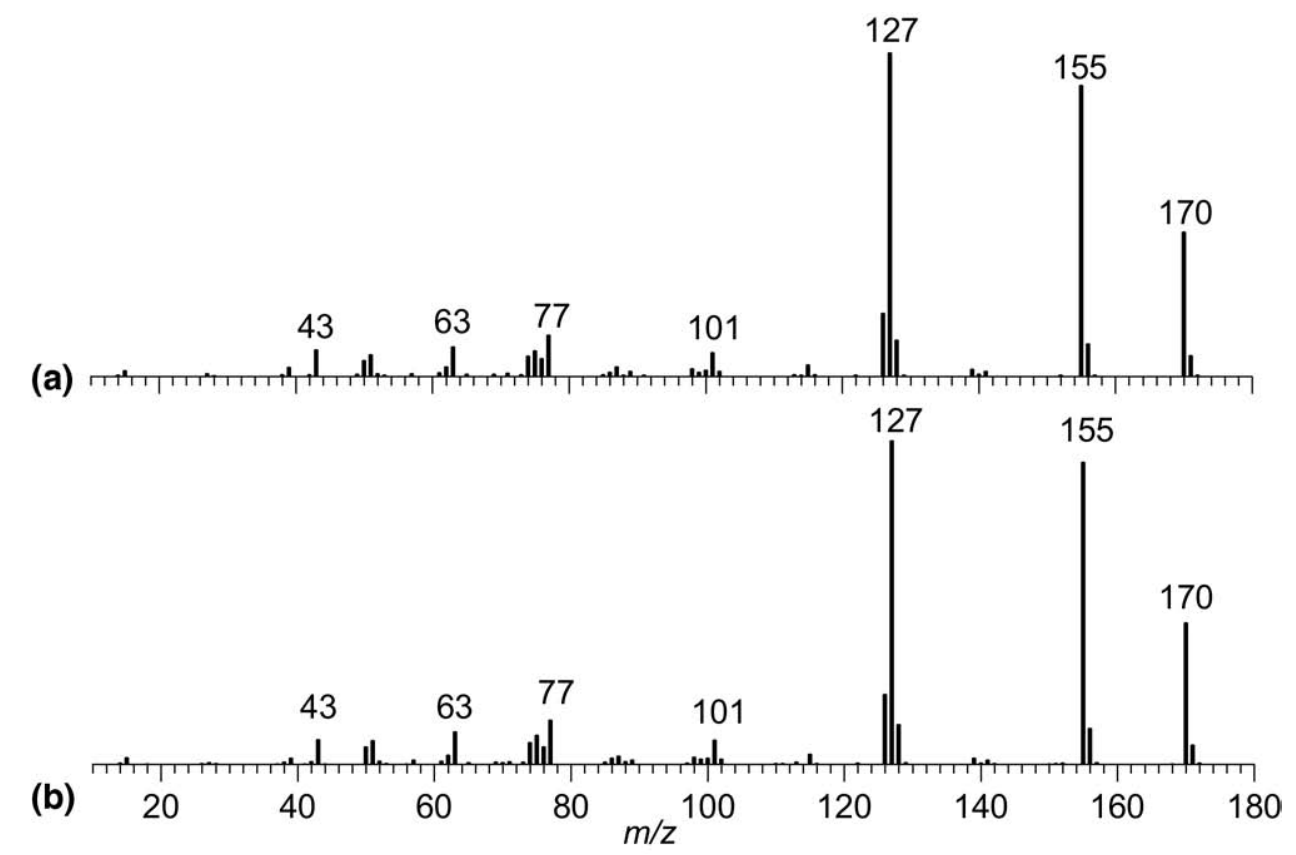

Figure 1. EI-MS at $70 \mathrm{eV}$ of the isomeric (a) $\alpha$ - and (b) $\beta$-acetonaphtones. 


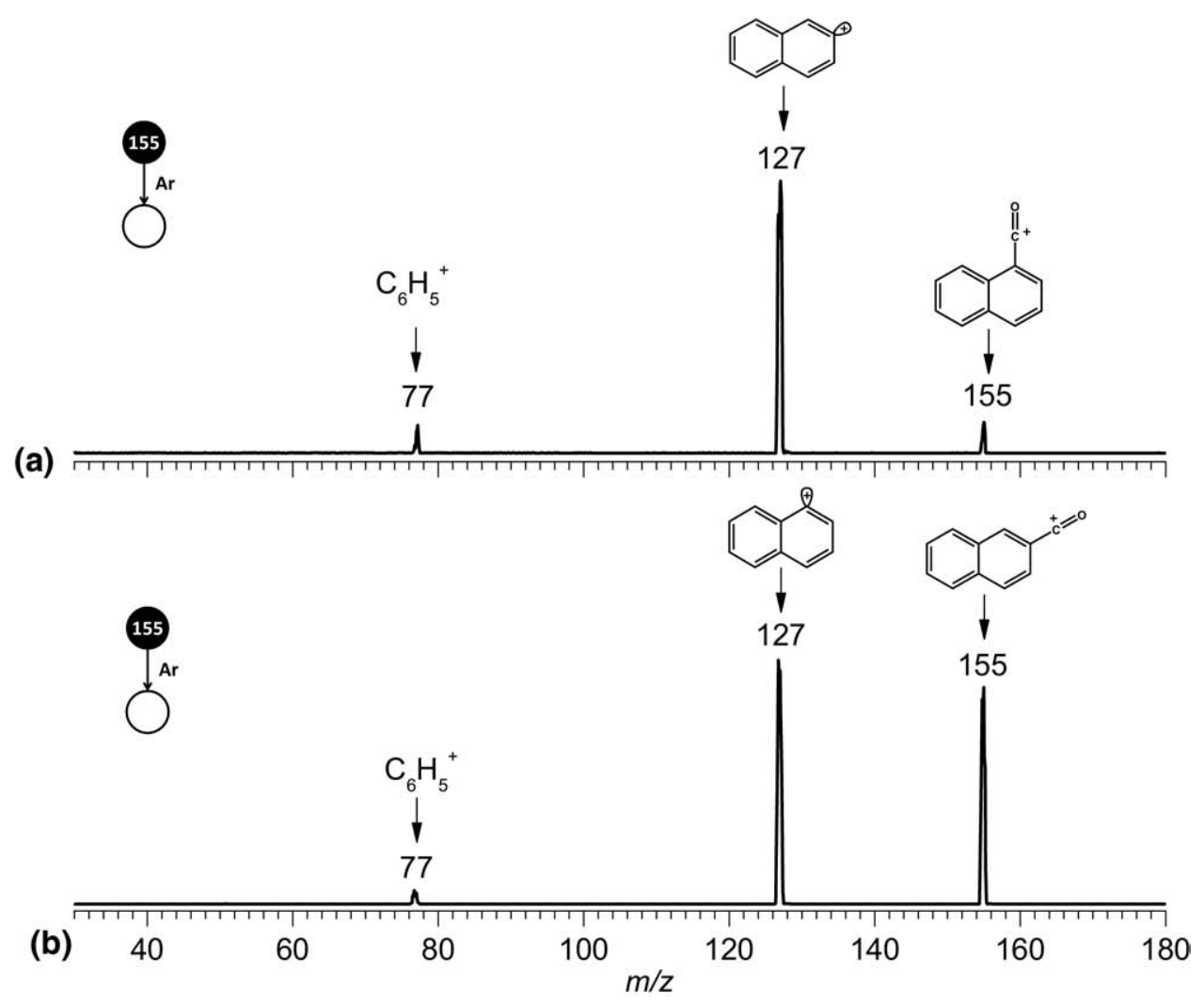

Figure 2. $\mathrm{MS}^{2}$ for CID of the $\alpha / \beta$ isomers (a) $\mathbf{1 a}$ and (b) $2 \mathbf{a}$ of $m / z 155$.

can be found in the electronic version of this article) but very similar ion chemistry was also observed. Both ions of $\mathrm{m} / \mathrm{z} 199$ dissociated by CID mainly by the loss of a neutral acetaldehyde molecule (44 Da) likely regenerating the parent acylium ion of $m / z 155$.

\section{$\left[4+2^{+}\right]$Polar Cycloaddition Reactivity \\ Towards Isoprene}

Many types of acylium ions have been found to also react promptly through $\left[4+2^{+}\right]$cycloadditions with dienes [35-38] and O-heterodienes [39]. Reactions of 1a and 2a with isoprene were therefore tested. Figure 4 shows that both isomers do react to form the expected $\left[4+2^{+}\right]$cycloadducts of $\mathrm{m} / \mathrm{z} 223$ (Scheme 3), but unfortunately the set and abundances of product ions and sequential product ions (Figure S2) were again very similar for both isomers.

\section{Reactivity Towards Nitriles}

Acylium ions have also been found to react extensively with nitriles by double addition to form cyclic 1,3,5oxidiazinium ions [40] (Scheme S1). Figures S3 and S4 show the mass spectra obtained when 1a and 2a were reacted with acetonitrile and propionitrile, respectively. We first performed ion/molecule reactions with acetonitrile but due to the lack of conclusive results, propionitrile was also tested. Unfortunately, both isomeric ions were found to be relatively inert towards the two nitriles and to produce similar $\mathrm{MS}^{2}$ data. The main process, despite the near $0 \mathrm{eV}$ collision energy used, was CID via the loss of $C O$ leading to the respective fragment ions $\mathbf{1} \mathbf{b}$ and $\mathbf{2} \mathbf{b}$ of $\mathrm{m} / \mathrm{z} 127$ and their subsequent reaction by single addition to a nitrile molecule. For acetonitrile, the main product was that of $\mathrm{m} / \mathrm{z} 168$ (Figure S3). For proprionitrile, the main products were that of $\mathrm{m} / \mathrm{z} 182$ from single addition and an abundant ion of $m / z 167$ formed by further loss of a methyl radical (Figure S4). Again, in a further attempt to achieve differentiation of $\mathbf{1 a}$ and $\mathbf{2 a}$, the $\mathrm{MS}^{3}$ for CID of their secondary and isomeric product ions from single nitrile addition were also collected (Figures S5 and S7). Unfortunately again, very similar spectra were collected with the naphthyl cations $\mathbf{1 b}$ or $\mathbf{2} \mathbf{b}$ of $\mathrm{m} / \mathrm{z} 127$ as the major fragments.

The results presented so far show that the potential SDFI 1a and 2a represents a very challenging isomeric pair for distinction based on unimolecular and bimolecular ion chemistry. Ethyl vinyl ether was then tested. This molecule has been used extensively in diagnostic ion/molecule reactions and found able to distinguish several classes of isomers [41, 42]. For instance, protonated cyclohexene epoxides were distinguished from protonated ketones, esters, ethers and alcohols by reaction with ethyl vinyl ether, which added promptly and selectively to the protonated cyclohexene epoxide [43]. Protonated $\beta$-hydroxy ketones were also found to react 
(a)
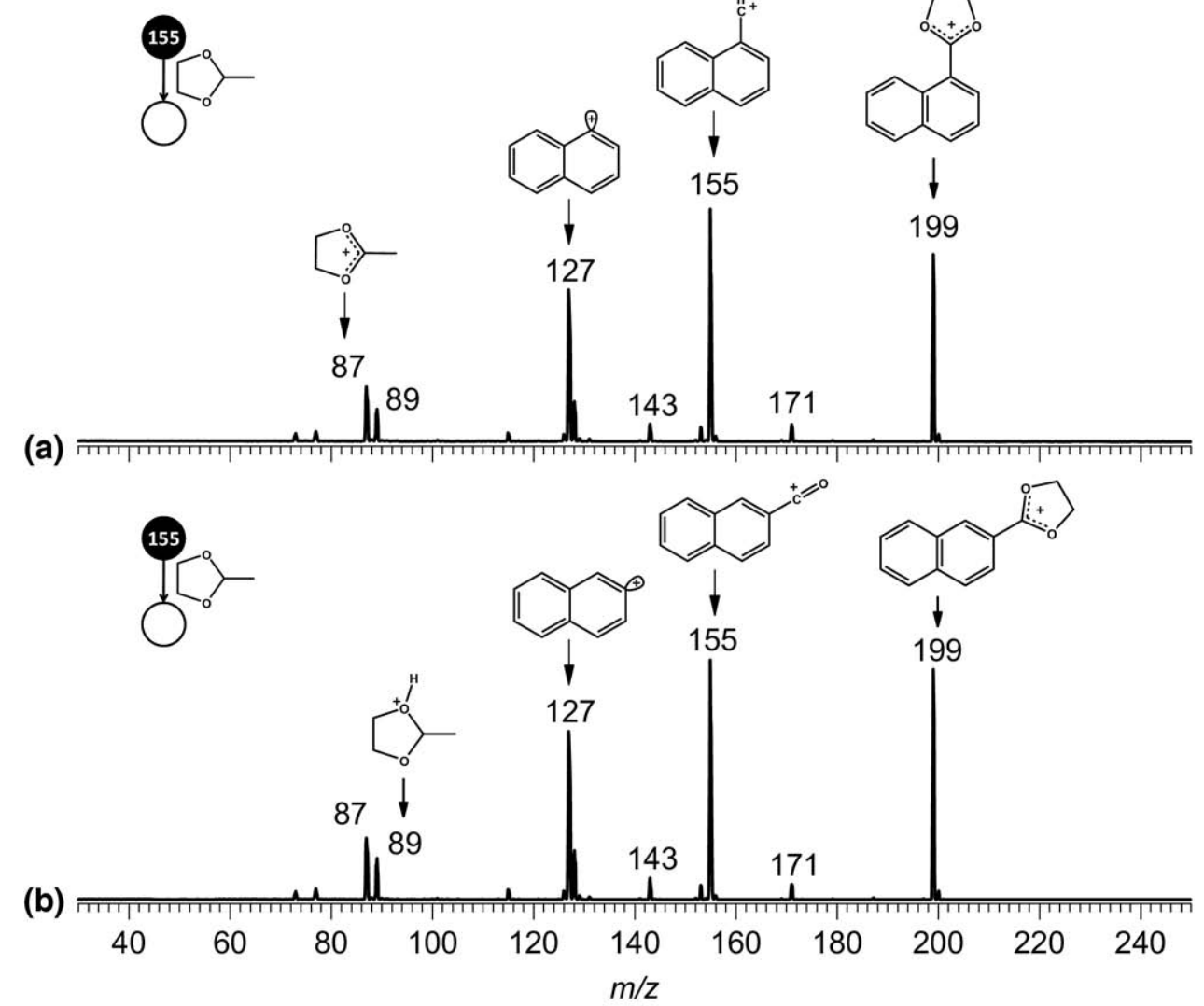

Figure 3. $\mathrm{MS}^{2}$ for the reaction of the $\alpha / \beta$ isomers (a) 1a and (b) 2a of $\mathrm{m} / \mathrm{z} 155$ with 2-methyl-1,3dioxolane (88 Da).

selectively with ethyl vinyl ether to form cyclic products [11]. Structurally diagnostic ion/molecule reactions of ethyl vinyl ether with specific fragment ions generated from explosives such as trinitrotoluene (TNT) and hexahydro-1,3,5-trinitro-1,3,5-triazine (RDX) were also used for selective detection [44]. Reactions of ethyl vinyl ethers have also been used to characterize azabutadiene cations via $\left[4^{+}+2\right]$ cycloaddtions [45].

\section{Reactivity Towards Vinyl Ethers}

Fortunately, as Figure 5 shows, structurally diagnostic product ions were formed for the $\alpha$-isomer 1a via a cascade of ion/molecule reactions with ethyl vinyl ether intercalated with dissociations (Scheme 4). The $\mathrm{MS}^{2}$ for the $\alpha$-isomer 1a (Figure 5a) shows two unique product ions of $m / z 165$ and 181, which are not observed for the $\beta$-isomer $2 \mathbf{a}$ (Figure $5 b$ ). A common product ion of $\mathrm{m} / \mathrm{z} 253$ is formed by both isomers, and Scheme 4 rationalizes the mechanisms of its formation. Ethyl vinyl ether adds to 1a of $\mathrm{m} / \mathrm{z} 155$ to form an unstable (undetected) adduct of $\mathrm{m} / \mathrm{z} 227$ which, as facilitated by its $\alpha$-configuration, undergoes fast cyclization via ring addition and loss of ethanol to form the very stable and fully delocalized hydroxyl phenalenium ion of $m / z 181$. A second addition of ethyl vinyl ether followed by the loss of ethanol could then be envisaged to form the product ion of $\mathrm{m} / \mathrm{z} 253$, which dissociates by the neutral loss of 2-ethoxyacetaldehyde (88 Da) to form the second unique product ion of $m / z 165$.

In accordance with the proposed reactivity, the CID behavior of the isomeric product ions of $m / z 253$ (Figure

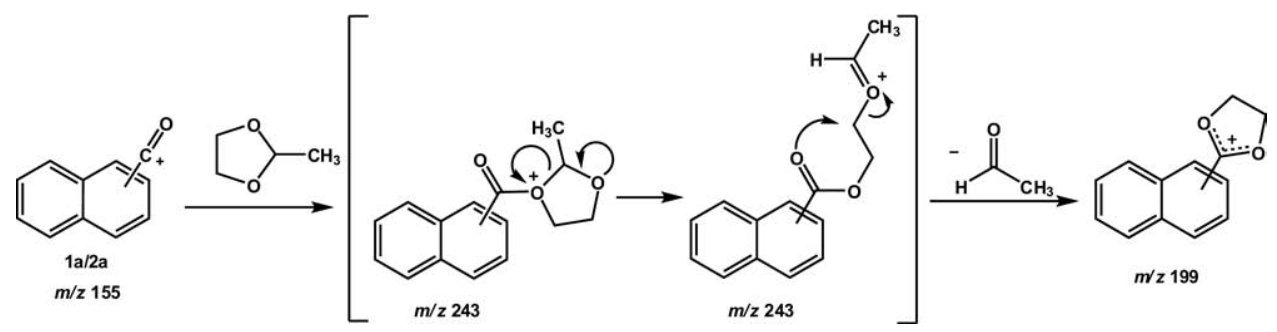

Scheme 2 
(a)

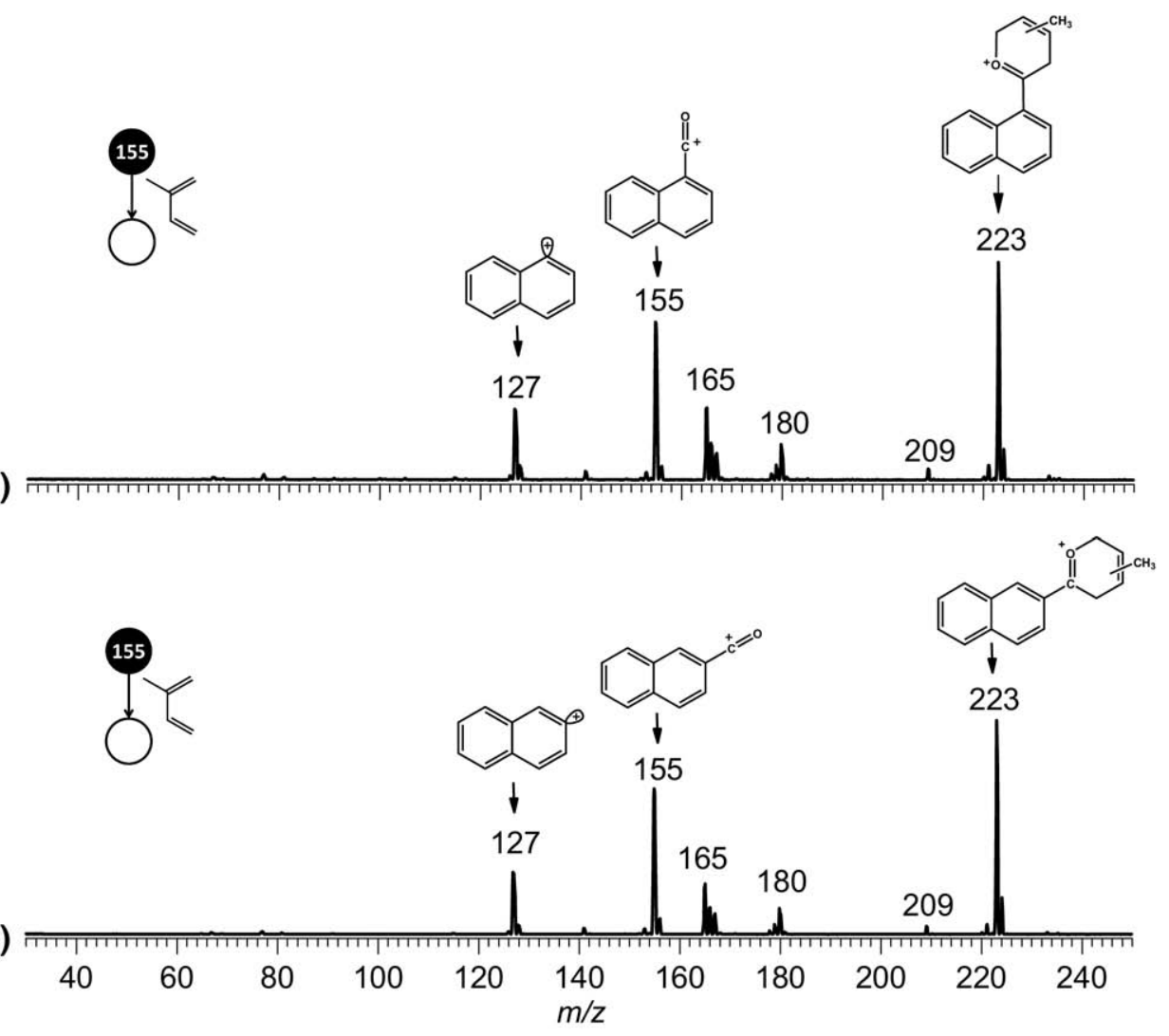

Figure 4. $\mathrm{MS}^{2}$ for the reaction with isoprene (68 Da) of the $\alpha / \beta$ isomers (a) $1 \mathbf{a}$ and (b) $2 \mathbf{a}$ of $\mathrm{m} / \mathrm{z} 155$.

6) were also distinctive. That from 1a (Figure 6a) dissociates as proposed (Scheme 4) to form the two unique ions of $\mathrm{m} / \mathrm{z} 181$ and 165 , whereas the isomeric product ion of $m / z 253$ from 2 a dissociates solely to the parent ion 2a of $\mathrm{m} / \mathrm{z} 155$ (Figure 6b). As also expected due to their very stable resonance stabilized structures, both ions of $\mathrm{m} / \mathrm{z} 181$ and 165 show great resistance towards dissociation when subjected to CID via $\mathrm{MS}^{3}$ experiments (Figures S8 and S9).

To gain further evidence about the mechanism of the structurally diagnostic reaction with ethyl vinyl ether, several homologue vinyl ethers were also tested. Figure S10 shows the $\mathrm{MS}^{2}$ for the reaction of $\mathbf{1 a}$ and $\mathbf{2} \mathbf{a}$ with propyl vinyl ether (86 Da). As expected, the $\alpha$-isomer 1a displayed the unique set of product ions of $m / z 181$ and 165 , the same set formed with ethyl vinyl ether (Figure $5 a)$, whereas the common product ion was shifted corresponding from $\mathrm{m} / \mathrm{z} 253$ to $\mathrm{m} / \mathrm{z} 267$ (Scheme S4). The
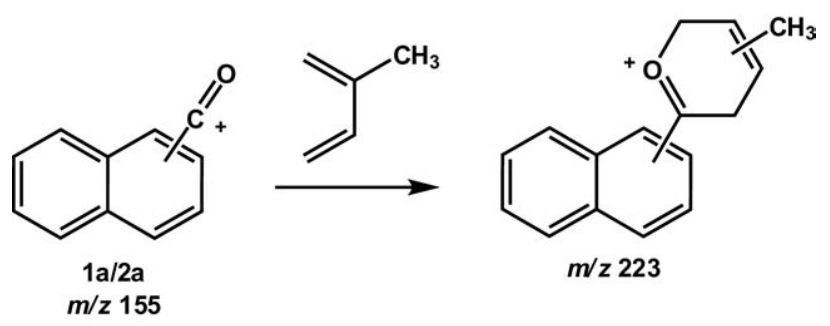

Scheme 3 product ion of $m / z 267$ from 1a also uniquely dissociates to the ions of $m / z$ 155, 165, and 181 (Figure S11).

Similar results, with the expected $+14 \mathrm{~m} / \mathrm{z}$ units shift for the two diagnostic ions, were also obtained in reactions with ethyl 1-propenyl ether (see Figure 7 and Figure S12). Isobutyl vinyl ether, tert-butyl vinyl ether, allyl ethyl ether, and ethyl vinyl sulfide were also tested and the results (Figures S13-S16) nicely confirm the proposed mechanism and the ability of vinyl ethers to unambiguously differentiate the two SDFI 1a and 2a.

\section{A Single Test Molecule: Absolute Assignment of Either $\alpha$ - or $\beta$-Acyl Configuration}

To test the method proposed herein, methyl 4-(1-naphthyl)2,4-dioxobutanoate (see structure below) was selected so as to "mimic" a single molecule of an acylnaphthalene with an "unknown" configuration. When submitted to $70 \mathrm{eV}$ EI ionization, the molecule formed (as expected) the desired SDFI of $m / z 155$ (Figure S17) as an abundant fragment. The $\mathrm{MS}^{2}$ for CID of this ion (not shown) was very similar to that of Figure 2, which confirms that the proper SDFI was indeed formed (either 1a or $\mathbf{2 a}$ supposing unknown configuration). This ion of $m / z 155$ was then reacted with the three vinyl ethers (Figure 7). Note the formation in all cases of the set of unique product ions expected for 1a. This structurally diagnostic reactivity unequivocally assigns, in 
(a)
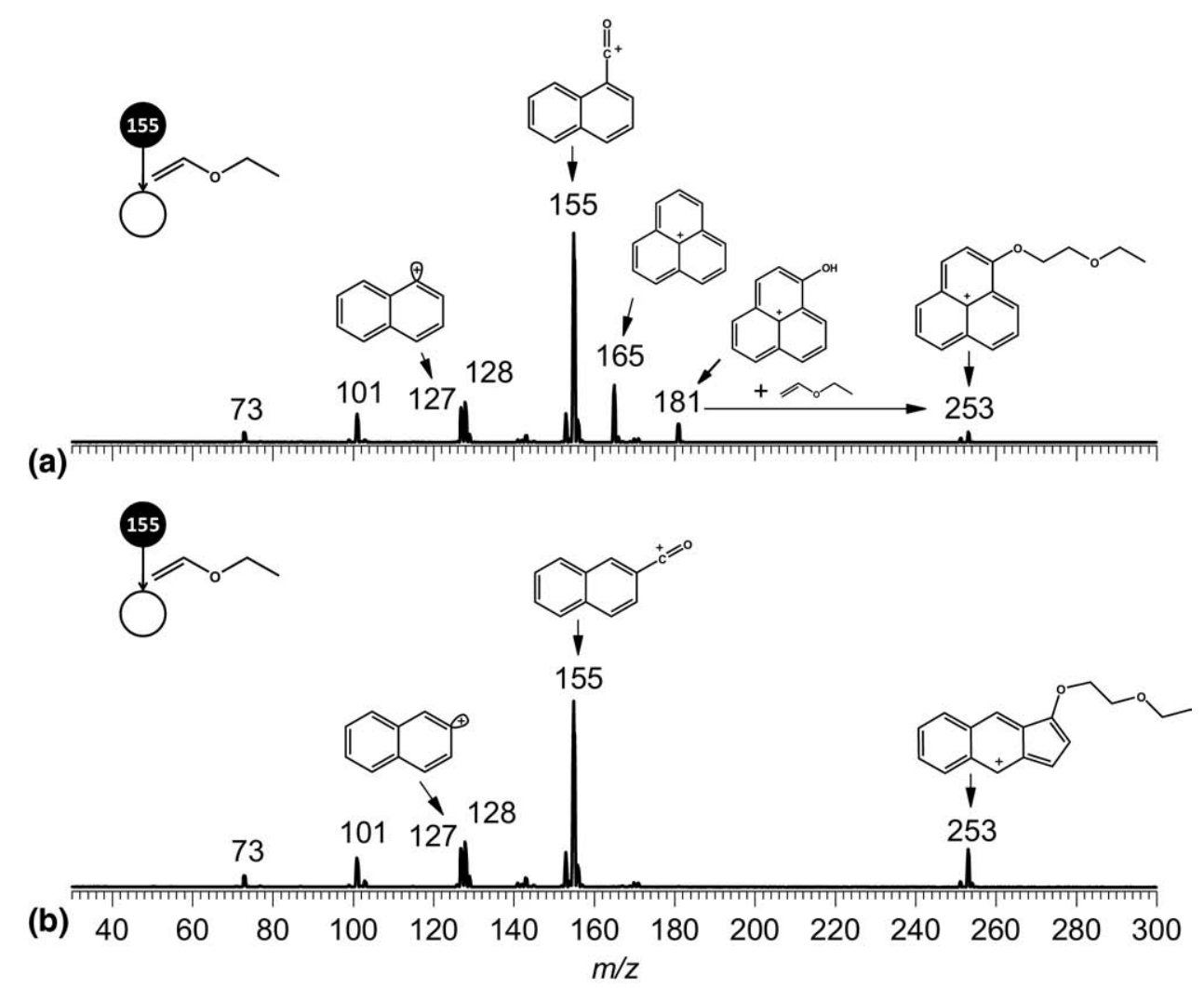

Figure 5. $\mathrm{MS}^{2}$ for the reaction with ethyl vinyl ether (72 Da) of the $\alpha / \beta$ isomers (a) 1a and (b) 2a of $m / z 155$.

an absolute fashion, the configuration of the single test molecule as an $\alpha$-isomer.<smiles>COC(=O)C(=O)CC(=O)c1cccc2ccccc12</smiles>

\section{Conclusions}

The $\alpha$ - (1a) or $\beta$-naphthoyl (2a) cations have been found to function as proper SDFI for the isomeric class of acyl naphthalenes. These molecules bear a carbonyl group directly attached to an aromatic ring and are therefore prone to form the relatively stable aromatic acylium ions $1 \mathbf{a}$ and $\mathbf{2 a}$ as abundant fragments upon ionization and dissociation. Seventy eV EI has been used in this study, but other ionization techniques such as ESI, APCI, APPI, MALDI, or GDI that produce protonated or ionized molecules should work as well to form the SDFI ions $\mathbf{1 a}$ or $\mathbf{2 a}$ due to in-source CID or when followed, if necessary, by MS ${ }^{2}$ CID experiments. First, CID of the ion of $\mathrm{m} / \mathrm{z} 155$ should be performed to confirm its identity as either 1a or $\mathbf{2 a}$. Second, ion/ molecule reactions with ethyl vinyl ether or other homologues should be performed. With ethyl vinyl ether, the $\alpha$-ion 1a will react to form a characteristic set of three product ions of $m / z 165,181$, and 253 . The

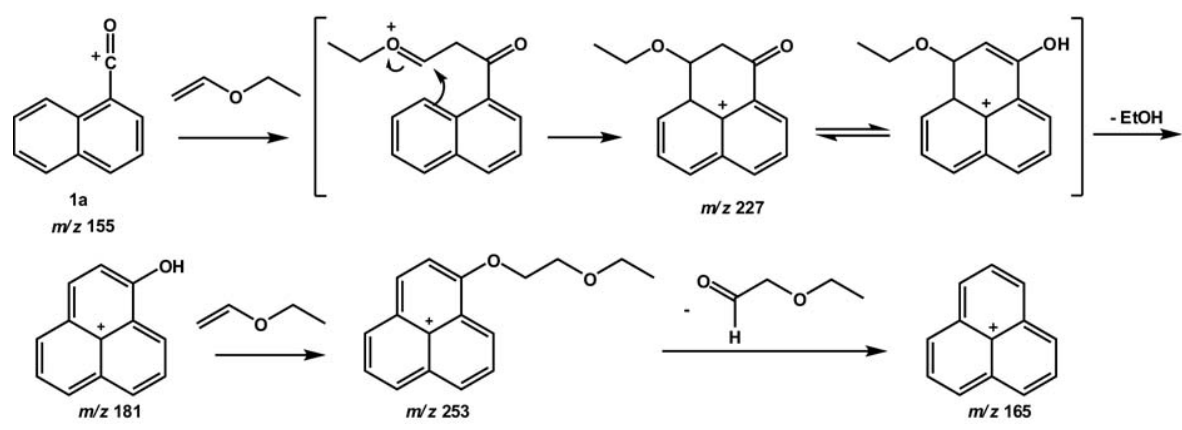

Scheme 4 
(a)

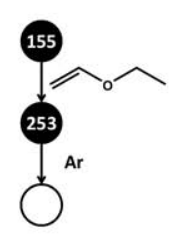

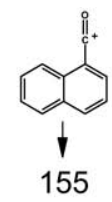
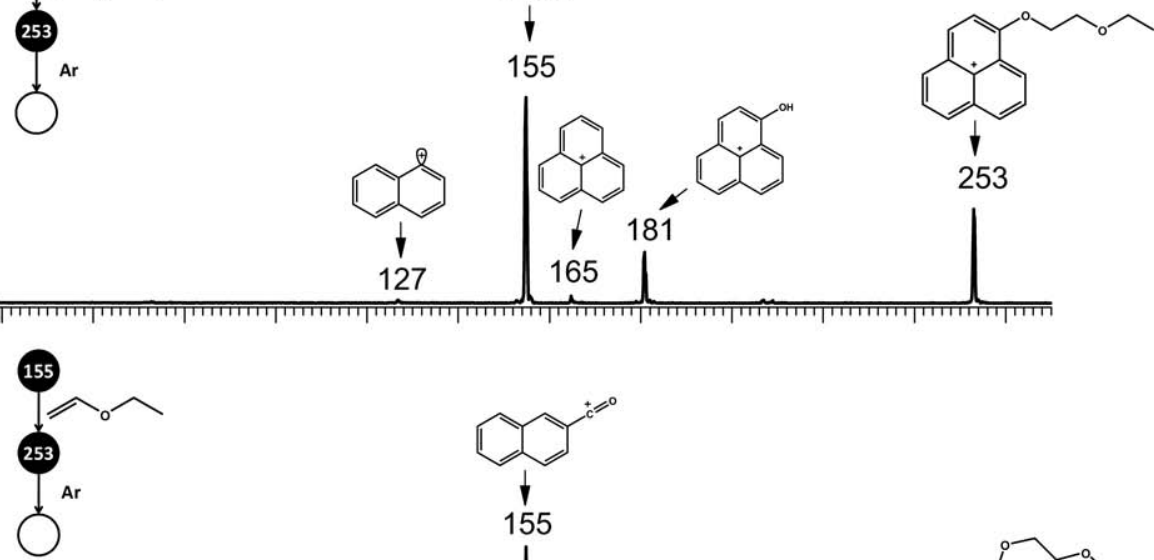

(b)

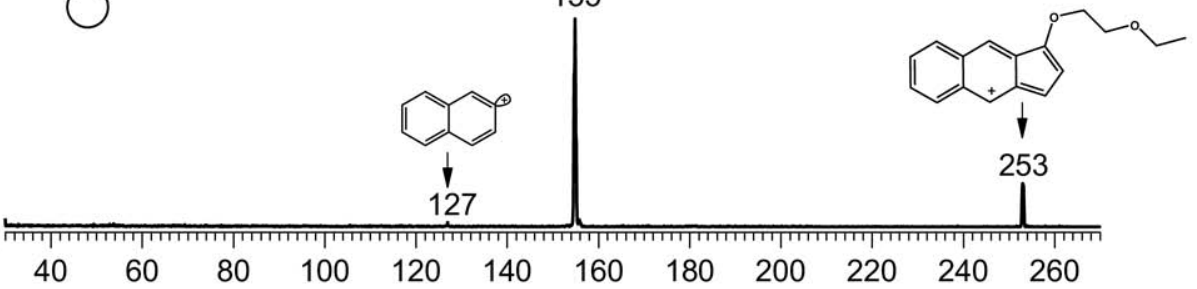

Figure 6. $\mathrm{MS}^{3}$ for CID of the isomeric product ions of $m / z 253$ formed in reactions with ethyl vinyl ether (72 Da) of the $\alpha / \beta$ isomers (a) 1a and (b) 2a of $m / z 155$.

(a)

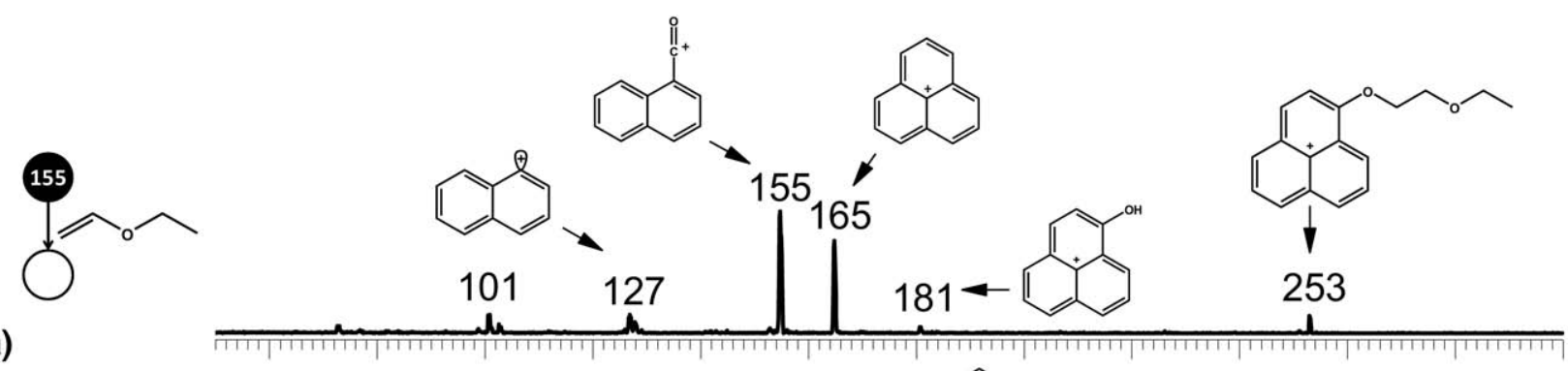

(b)<smiles>CCCOCCOCC</smiles>

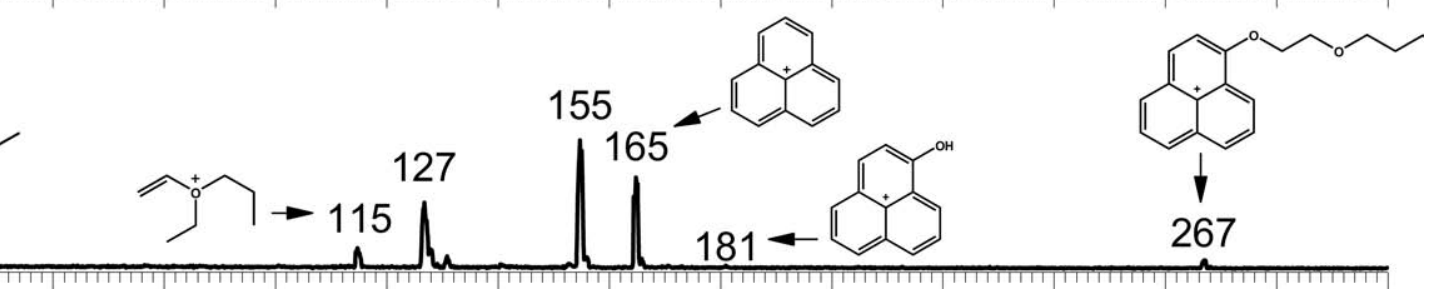

(c)<smiles>CCCC=COCC</smiles>

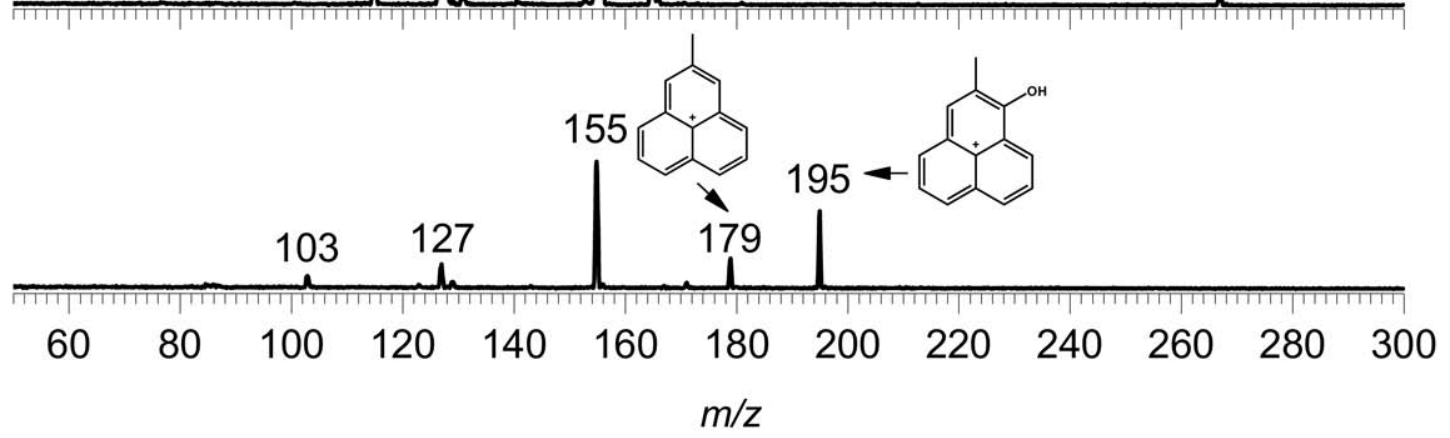

Figure 7. $\mathrm{MS}^{2}$ for ion/molecule reactions with (a) ethyl vinyl ether, (b) propyl vinyl ether, and (c) ethyl 1-propenyl ether of the $\alpha$-SDFI 1a of $\mathrm{m} / z 155$ generated from $70 \mathrm{eV}$ EI of the test molecule [methyl 4-(1-naphthyl)-2,4-dioxobutanoate]. 


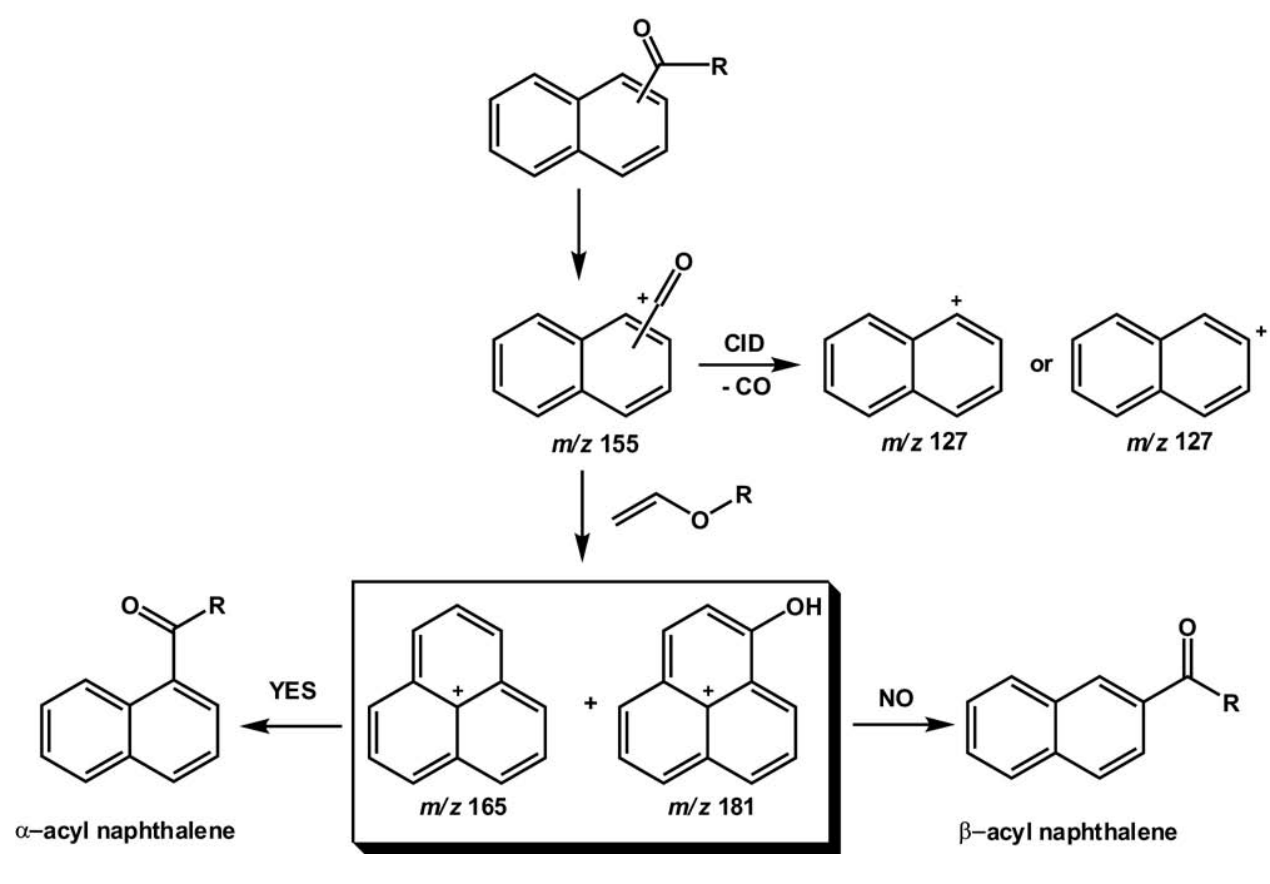

Scheme 5

$\beta$-ion 2a will form solely the ion of $m / z 253$. Further confirmation can also be attained via $\mathrm{MS}^{3}$ of the ion of $\mathrm{m} / \mathrm{z} 253$ (or its homologues). As Scheme 5 summarizes, an absolute MS-only method for the unambiguous assignment of configuration (either $\alpha$ - or $\beta$-substitution) individually applicable to members of the whole class of acyl naphthalenes has been therefore established.

\section{Acknowledgments}

The authors thank the Brazilian research foundations $\mathrm{CNPq}$, CAPES, and FAPESP for financial assistance. They also thank a reviewer for very helpful discussions on reaction mechanisms.

\section{Appendix A Supplementary Material}

Supplementary material associated with this article may be found in the online version at doi:10.1016/j. jasms.2010.08.019.

\section{References}

1. Zahedi-Tabrizi, M.; Fariba, T.; Moosavi-Tekyeh, Z.; Alireza, J.; Tayyari, S. F. Structure and Vibrational Assignment of the Enol Form of 1,1,1-Trifluoro-2,4-Pentanedione. Spectrochim. Acta Part A 2006, 65, 387396 .

2. Albert, K.; Dachtler, M.; Glaser, T.; Händel, H.; Lacker, T.; Schlotterbeck, G.; Strohschein, S.; Tseng, L.; Braumann, U. On-Line Coupling of Separation Techniques to NMR. J. High Resolut. Chromatogr. 1999, 22, 135-143.

3. Kühnle, M.; Holtin, K.; Albert, K. Capillary NMR Detection in Separation Science. J. Sep. Sci. 2009, 32, 719-726.

4. Benassi, M.; Corilo, Y. E.; Uria, D.; Augusti, R.; Eberlin, M. N. Resolution and Recognition of Isomeric Alkyl Anilines by Mass Spectrometry. J. Am. Soc. Mass Spectrom. 2009, 20, 269-277.

5. Benassi, M.; Eberlin, M. N. Using Structurally Diagnostic Fragment Ions to Distinguish Constitutional Isomers by MS ${ }^{2}$ : The Case of $\alpha$-Acylnaphthones and $\beta$-acylnaphthones. Proceedings of the 55th Conference of the American Society for Mass Spectrometry; Indianapolis, IN, June, 2007.
6. Moraes, L. A. B.; Sabino, A. A.; Meurer, E. C.; Eberlin. M. N. Absolute Configuration Assignment of Ortho, Meta, or Para Isomers by Mass Spectrometry. J. Am. Soc. Mass Spectrom. 2005, 16, 431-436.

7. Gozzo, F. C.; Eberlin, M. N. 2-Pyridyl and 2-Pyrimidyl Cations. Stable $o$-Hetarynium Ions in the Gas Phase. J. Org. Chem. 1999, 64, 2188-2193.

8. Carvalho, M.; Gozzo, F. C.; Mendes, M. A.; Sparrapan, R.; Kascheres, C. Eberlin, N. Locating the Charge Site in Heteroaromatic Cations. Chem. Eur. J. 1998, 4, 1161-1168.

9. Da Rocha, L. W.; Sparrapan, R.; Augusti, R.; Eberlin, M. N. Direct Assignment of Positional Isomers by Mass Spectrometry: Ortho-, Meta-, and Para-Acyl and Amidyl Anilines and Phenols and Derivatives. J. Mass Spectrom. 2004, 39, 1176-1181.

10. Sparrapan, R.; Eberlin, M. N.; Augusti. R. Locating the Charge Site in Isomeric Pyrrolyl Ions by the Eberlin Ion/Molecule Reactions. Rapid Commun. Mass Spectrom. 2005, 19, 1775-1778.

11. Begala, M.; Tocco, G.; Meli, G.; Podda, G.; Urru, S. A. M. Formation of 2-Substituted Benzofuran Fragment Ions from 6-Alkyl and 6Aryldibenzo(d,f)(1,3)Dioxepine Derivatives under Electron Ionization-a Useful Precursor Ion for Isomeric Differentiation. J. Mass Spectrom. 2009, 44, 245-251.

12. Eberlin, M. N. Structurally Diagnostic Ion/Molecule Reactions: Class and Functional-Group Identification by Mass Spectrometry. J. Mass Spectrom. 2006, 41, 141-156.

13. Brodbelt, J. S. Analytical Applications of Ion-Molecule Reactions. Mass Spectrom. Rev. 1997, 16, 91-110.

14. Gronert, S. Mass Spectrometric Studies of Organic Ion/Molecule Reactions. Chem. Rev. 2001, 101, 329-360.

15. Staley, R. H.; Corderman, R.R.; Foster, M. S.; Beauchamp, J. L. Nucleophilic Attack on Protonated Oxiranes in Gas Phase Identification of $\mathrm{C}_{2} \mathrm{H}_{5} \mathrm{O}^{+}$Isomeric Ion Corresponding to Protonated Ethyleneoxide. J. Am. Chem. Soc. 1974, 96, 1260-1261.

16. Munson, M. S. B.; Field, F. H. Chemical Ionization Mass Spectrometry I. General Introduction. J. Am. Chem. Soc. 1966, 88, 2621-2630.

17. Drewery, C. J.; Jennings, K. R. Ion-Molecule Reactions in the Vinyl Methyl Ether System Studied by Ion Cyclotron Resonance Mass Spectrometry. Int. J. Mass Spectrom. Ion Phys. 1976, 19, 287-291.

18. Van Doorn, R.; Nibbering, N. M. M.; Ferrer-Correia, A. J. V.; Jennings, K. R. Evidence for a [2 + 4] Cycloaddition in the Ion-Molecule Reaction of Ionized 1,3-Butadiene with Vinyl Ethyl (Methyl) Ether in the Gas Phase. Org. Mass Spectrom. 1978, 13, 729-732.

19. Groenewold, G. S.; Gross, M. L. Reaction of the Vinyl Methyl Ether Cation Radical and 1,3-Butadiene: A Two-step Cycloaddition. J. Am. Chem. Soc. 1984, 106, 6575-6579.

20. Gross, M. L.; Lin, P. H.; Franklin, S. J. Analytical Applications of Ion-Molecule Reactions: Identification of $\mathrm{C}_{5} \mathrm{H}_{10}$ Isomers by Ion Cyclotron Resonance Spectrometry. Anal. Chem. 1972, 44, 974-978.

21. Bauerle G. F. Jr.; Hall, B. J.; Tran, N. V.; Brodbelt, J. S. Ion-Molecule Reactions of Oxygenated Chemical Ionization Reagents with Vincamine. J. Am. Chem. Soc. 1996, 7, 250-260.

22. Kenttämaa, H. I.; Cooks, R. G. Identification of Protonated $\beta$ Hydroxycarbonyl Compounds by Reactive Collisions in Tandem Mass Spectrometry. J. Am. Chem. Soc. 1989, 111, 4122-4123. 
23. Kempen, E. C.; Brodbelt, J. Use of Trimethyl Borate as a Chemical Ionization Reagent for the Analysis of Biologically Active Molecules. J. Mass Spectrom. 1997, 32, 846-854.

24. Dikusar, E. A.; Vashkevich, E. V.; Kozlov, N. G.; Potkin, V. I.; Moiseichuk, K. L.; Isakovich, O. I.; Yuvchenko, A. P. Peroxy-Containing Acetylenic Alcohols and Ethers Derived from 4-Methoxybenzophenone and 1- and 2-acetonaphthones. Russ. J. Gen. Chem. 2003, 73, 586-590.

25. Keskin, S.; Arsu, N. Using 2-(N-Methyl-N-Phenylamino)Acetonaphthone as Photoinitiator for the Polymerization of Methyl Methacrylate. Polym. Bull. 2006, 57, 643-650.

26. Singh, A. K.; Khade, P. K. 2-Acetonaphthone and Anthracene-9-Methanol Based Phototriggers for Caging Applications. .Am. Chem. Soc. 2006, 231, 257-257, Abstracts.

27. Nguyen, T. T.; Le, T. N.; Hansen, P. E.; Duus, F. Preparation and Structural Characterization of New Class of Stable Thioketones: OrthoHydroxythiocetophenones. Tetrahedron Lett. 2006, 47, 8433-8435.

28. Hoffmann, N. New Photochemical Rearrangements and Extrusion Reactions of Aromatic Compounds Induced by an Intramolecular [2 + 2] Photocycloaddition Between a Naphthalene and a Resorcinol Moiety. Tetrahedron 2002, 58, 7933-7941.

29. Juliano, V. F.; Gozzo, F. C.; Eberlin, M. N.; Kascheres, C.; Do Lago, C. L. Fast Multidimensional (3D and 4D) $\mathrm{MS}^{2}$ and $\mathrm{MS}^{3}$ Scans in a HighTransmission Pentaquadrupole Mass Spectrometer. Anal. Chem. 1996, 68, 1328-1334.

30. Eberlin, M. N. Triple Stage Pentaquadrupole (QqQqQ) Mass Spectrometry and Ion/Molecule Reactions. Mass Spectrom. Rev. 1997, 16, 113-144.

31. Moraes, L. A. B.; Eberlin, M. N. Transacetalization of 1,3-Dioxane with Acylium and Sulfinyl Cations in the Gas Phase. J. Chem. Soc., Perkin Trans. 1997, 2, 2105-2111.

32. Moraes, L. A. B.; Eberlin, M. N. Ketalization of Gaseous Acylium ions. J. Am. Soc. Mass Spectrom. 2001, 12, 150-162.

33. Moraes, L. A. B.; Mendes, M. A.; Sparrapan, R.; Eberlin, M. N. Transacetalization with Gaseous Carboxonium and Carbosulfonium Ions. J. Am. Soc. Mass Spectrom. 2001, 12, 14-22.

34. Meurer, E. C.; Sabino, A. A.; Eberlin, M. N. Ionic Transacetalization with Acylium Ions: A Class-Selective and Structurally Diagnostic Reaction for Cyclic Acetals Performed Under Unique Electrospray and Atmospheric Pressure Chemical Ionization In-Source Ion-Molecule Reaction Conditions. Anal. Chem. 2003, 75, 4701-4709.
35. Eberlin, M. N.; Cooks, R. G. Polar $\left[4+2^{+}\right]$Diels-Alder Cycloadditions of Acylium Ions in the Gas Phase. J. Am. Chem. Soc. 1993, 115, 9226-9233.

36. Eberlin, M. N. Gas-Phase Polar Cycloadditions. Int. J. Mass Spectrom. 2004, 235, 263-278.

37. Eberlin, M. N.; Majumdar, T. K.; Cooks, R. G. Structures and Mechanisms of Reactions of Isomeric $\mathrm{C}_{2} \mathrm{H}_{3} \mathrm{O}^{+}$and $\mathrm{C}_{2} \mathrm{H}_{3} \mathrm{~S}^{+}$Ions Revealed Through Ion/Molecule Reactions in Conjunction with 2D and 3D Mass Spectrometry. J. Am. Chem. Soc. 1992, 114, 2884.

38. Lemos, A. B.; Sparrapan, R.; Eberlin, M. N. Reactions of Gaseous Acylium Ions with 1,3-Dienes: Further Evidence for Polar $\left[4+2^{+}\right]$ Diels-Alder Cycloaddition. J. Mass Spectrom. 2003, 38, 305-314.

39. Meurer, E. C. Eberlin, M. N. Mono- and Double-Polar $\left[4+2^{+}\right]$ Diels-Alder Cycloaddition of Acylium Ions with O-Heterodienes. J. Mass Spectrom. 2002, 37, 146-154.

40. Meurer, E. C.; Moraes, L. A. B.; Eberlin, M. N. Cyclization of Acylium Ions with Nitriles: Gas-Phase Synthesis and Characterization of 1,3,5Oxadiazinium Ions. Int. I. Mass Spectrom. 2001, 212, 445-454.

41. Meurer, E. C.; Sparrapan, R.; Eberlin, M. N. Gas-Phase Polar $\left[4^{+}+2\right]$ Cycloaddition with Ethyl Vinyl Ether: A Structurally Diagnostic IonMolecule Reaction for 2-Azabutadienyl Cations. J. Mass Spectrom. 2003, 38, 1075-1080.

42. Williams, V. M.; Kong, J. R.; Ko, B. J.; Mantri, Y.; Brodbelt, J. S. Baik, M. H.; Krische, M. J. ESI-MS, DFT, and Synthetic Studies on the $\mathrm{H}_{2}$-Mediated Coupling of Acetylene: Insertion of $\mathrm{C}=\mathrm{X}$ Bonds into Rhodacyclopentadienes and Brønsted Acid Co-Catalyzed Hydrogenolysis of Organorhodium Intermediates. J. Am. Chem. Soc. 2009, 131, 16054-16062.

43. Kenttämaa, H. I.; Pachuta, R. R.; Rothwell, A. P.; Cooks, R. G. Experimental Study of the Potential Energy Surface of the Protonated Cyclohexene Oxide/Cyclohexanone System. Isomerization, Dissociation, and Ion-Molecule Reactions of the Isolated Ions in the Gas Phase. J. Am. Chem. Soc. 1989, 111, 1654-1665.

44. Meurer, E. C.; Chen, H.; Riter, L.; Cotte-Rodriguez, I.; Eberlin, M. N. Cooks, G. Gas-Phase Reactions for Selective Detection of the Explosives TNT and RDX. Chem. Commun. 2004, 1, 40-41.

45. Augusti, R.; Gozzo, F. C.; Moraes, L. A. B.; Sparrapan, R.; Eberlin, M. N. The Simplest Azabutadienes in their N-Protonated Forms. Generation, Stability, and Cycloaddition Reactivity in the Gas Phase. J. Org. Chem. 1998, 63, 4889-4897. 